\title{
The effect of nutritional training, nutritional guidelines and a healthy eating policy on nutritional practices in full-day-care preschools in Dublin North West
}

\author{
A. Jennings ${ }^{1}$, S. McEvoy ${ }^{2}$ and C. Corish ${ }^{1}$ \\ ${ }^{1}$ School of Biological Sciences, Dublin Institute of Technology, Kevin Street, Dublin 8, Republic of Ireland and ${ }^{2}$ Health \\ Promotion Unit, Health Service Executive Dublin North East, North Circular Road, Dublin 7, Republic of Ireland
}

Full-day-care preschools contribute significantly to the nutritional intake and acquisition of dietary habits of the preschool child. However, Irish preschools are not obliged to structure their nutritional practices in line with the Food and Nutrition Guidelines for Pre-school Services $^{(1)}$, resulting in variable dietary practices, many of which are not conducive to good health.

The present study has investigated the influence of nutritional training, the possession of the guidelines and the existence of a written healthy eating policy on food provision and dietary practices in full-day-care preschools in Dublin North West ( $n$ 54). Results from a telephone questionnaire of preschool managers were analysed using $\chi^{2}$ tests for independence (or Fisher's exact probability tests) via SPSS for Microsoft Windows (version 14.0; SPSS Inc, Chicago, IL, USA), and are outlined in the Table.

\begin{tabular}{|c|c|c|c|c|}
\hline & \multirow[b]{2}{*}{$n$} & \multicolumn{3}{|c|}{$P$} \\
\hline & & $\begin{array}{c}\text { Training } \\
(n \text { 40) }\end{array}$ & $\begin{array}{l}\text { Guidelines } \\
\quad(n \text { 40) }\end{array}$ & $\begin{array}{l}\text { Policy } \\
\left(\begin{array}{ll}n & 34\end{array}\right)\end{array}$ \\
\hline \multicolumn{5}{|l|}{ Nutritional practices: } \\
\hline Nutritional training attendance & 40 & - & $0.013^{*}$ & 1.000 \\
\hline Possession of the guidelines & 40 & $0.013 *$ & - & 0.288 \\
\hline Presence of a healthy eating policy & 34 & 1.000 & 0.288 & - \\
\hline Parental involvement in policy development & 11 & 0.416 & 0.380 & - \\
\hline Parental involvement in menu planning & 26 & 1.000 & 0.057 & 0.535 \\
\hline Staff involvement in policy development & 14 & 0.218 & 0.101 & - \\
\hline Staff involvement in menu planning & 19 & 1.000 & 0.257 & 0.752 \\
\hline Adherence to regulations (two meals and two snacks daily) & 41 & 1.000 & 1.000 & 0.329 \\
\hline Dietary intake (children aged $<1$ year): & 35 & & & \\
\hline Weaning at 4-6 months & 32 & 0.499 & 1.000 & 1.000 \\
\hline Beaker introduction at 6 months & 16 & 0.415 & $0.043^{*}$ & $0.032 *$ \\
\hline Use of proprietary baby foods & 31 & 1.000 & 1.000 & 0.279 \\
\hline Dietary intake (children aged $1-5$ years): & 54 & & & \\
\hline Provision of chocolate or sugar-coated cereals & 8 & 0.176 & 1.000 & 0.118 \\
\hline Use of processed meat & 43 & 0.560 & 0.566 & 0.597 \\
\hline Provision of biscuits as a snack & 31 & 0.316 & $0.008^{*}$ & 0.0348 \\
\hline
\end{tabular}

Possession of the guidelines increased with training attendance. However, food provision and most dietary practices were not influenced by training, possession of the guidelines or the presence of a nutritional policy. In addition, unanticipated results were revealed, including the greater incidence of serving biscuits with possession of the guidelines and inappropriate beaker introduction with the presence of a policy.

Current preschool nutritional training is received by preschool staff with great interest, as highlighted by good attendance. However, community dietitians continually face barriers to the provision of optimal training, including the poor baseline nutritional knowledge of staff, high staff turnover and limited whole staff involvement in dietary practices, e.g. in policy and menu development. Variable nutritional policies also exist, many of which are not enforced, and possession of the guidelines does not consistently result in their use.

Whilst disparity in the baseline nutritional knowledge of pre-school staff secondary to the variability in general child-care training warrants attention, current nutritional training should aim to increase whole staff familiarity with and use of the guidelines, in addition to encouraging both nutritional policy development and enforcement and parental involvement in dietary practices.

1. Department of Health and Children (2004) Food and Nutrition Guidelines for Pre-school Services. Dublin: Health Promotion Unit. 